\title{
Development of a Remote Laboratory Management System and Integration with Social Networks
}

\author{
http://dx.doi.org/10.3991/ijes.v2i3.3821 \\ F. Lerro ${ }^{1}$, P. Orduña ${ }^{2}$, S. Marchisio ${ }^{1}$ and J. García-Zubía ${ }^{2}$ \\ ${ }^{1}$ Universidad Nacional de Rosario, Rosario, Argentina \\ ${ }^{2}$ University of Deusto, Bilbao, Spain
}

\begin{abstract}
The focus of this contribution is to propose a novel centralized authentication and authorization system, which can be used to share laboratories. This system optionally relies on existing mechanisms, such as those used by universities -e.g., Shibboleth, OpenID- or by social networks -e.g., Facebook Connect or Google with OAuth-. However, it still supports schools or universities not counting with an existing system, by providing its own system. The authentication and authorization system will be registered in other RLMSs. This way, users registered in the central system can consume laboratories from other institutions. This development is part of a project that includes the integration of the FCEIA-UNR lab with social networks. Based upon a previous development of a Remote Laboratory Management System at Universidad de Deusto, the authors also explain the advantages and drawbacks of the centralized approach.
\end{abstract}

Index Terms-Authentication and authorization, Engineering education, Remote Laboratory Management Systems.

\section{INTRODUCTION}

The convergence of information and communication technologies is one of the core elements of the "knowledge society". By using the diverse resources we have available, we access to new representational and communicational ways, as well as new conditions for transfer, access and use of information.

It is necessary to conduct studies and researches on educational potential of these resources, to take advantage of them properly as educational media.

Within the knowledge society, Web 2.0, social web, or $\mathrm{read} / \mathrm{write}$ web has gained increasing popularity. Both, students and teachers use them for different purposes: socialization, entertainment, communication and collaborative production. So, regardless of educational content involved, e-learning offered by the active participation and collaboration of students and teachers in the production of knowledge, is becoming an important teaching strategy.

Moreover, in the scientific technologic experimental training, the role of the practice laboratory is essential. Such a role can be associated with the fact that engineering requires good hands-on skills by interacting with things and phenomena in authentic situations. It can also be associated with the need of both, a well-built body of knowledge about materials, devices, equipment and tech- niques, and skills that involve modeling, design, problem solving, critical observation and analytical thinking.

Besides, there is a wide variety of laboratories available, which improve the training through real experimentation with remote access. Furthermore, nowadays it has become common on Remote Laboratories to be shared between different institutions. So, remote laboratories that started as simple experiments had become on big repositories with multiple experiments from different parts of the world merging remote and virtual labs as well. As it has been introduced on previous works, these primitive laboratories are now Remote Laboratory Management Systems [1]. The RLMS arose precisely aiming this objective: building tools that other remote laboratory could use to develop new remote laboratories

The focus of this contribution is to propose a novel centralized authentication and authorization system, which can be used to share laboratories. This system optionally relies on existing mechanisms, such as those used by universities -e.g., Shibboleth, OpenID- or by social networks -e.g., Facebook Connect or Google with OAuth-.

However, it still supports schools or universities not counting with an existing system, by providing its own system. It is necessary that the management system allows each institution to manage different levels of user privileges: Administrator, Tutor, Teacher, Student, etc. The authentication and authorization system will be registered in other RLMSs. In this way, users registered in the central system can consume laboratories from other institutions.

\section{THE SCENARIO}

At the Facultad de Ciencias Exactas, Ingeniería y Agrimensura of the Universidad Nacional de Rosario (UNR) we developed the FCEIA-UNR Remote Laboratory. It has two remote laboratories (Electronics Physics Lab and a Solar Water Heater). 


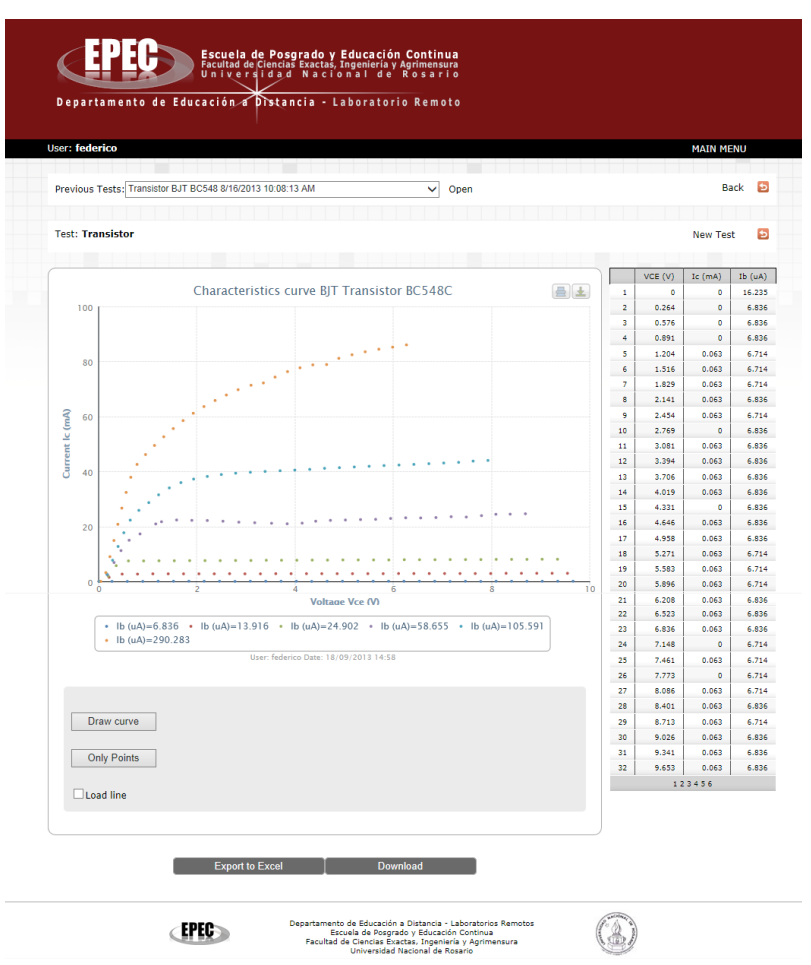

Figure 1. Electronics Physics FCEIA Remote Laboratory

From a didactic point of view we think the remote lab has become a useful source/tool to integrate "learning sequences" [2]. Among the great variety of didactic resources, the remote laboratory is a tool "at the service of", that can be integrated at any time to support learning activities. Thus, it will be very important to use it as a didactic instrument, to articulate it within the syllabus and to relate it or to make it work with the other resources and didactic materials and proposals of activities, performed by means of one of the most popular LMS in Argentina: the "e-ducativa platform". This LMS integrates information services, news, messaging, chat, discussion forums, software repository, wikis, surveys, videoconferences, evaluations, marks, updated professors and students' data, schedule of events, among others.

Many students use social networking sites in a complementary way. In particular, Facebook is the communicative resource most used between the students of FCEIA Remote Lab. Because of this, integration with Facebook was one of the objectives of the project. While a remote lab or a RLMS could use these technologies directly, the proposed framework hides the details of these systems providing a single point of access to all of them adapted to the particular domain of remote laboratories. For instance, Facebook itself is great for authentication given that most students are already there. However, remote laboratories also need certain mapping from concepts such as "this Facebook user is the teacher of this class compounded by this set of Facebook users"

Moreover, our FCEIA-UNR Remote Laboratory has been federated to WebLab-Deusto [1], so our users can access to their Laboratories as well as the ones that are connected to them. In the same way, WebLab-Deusto users can access the FCEIA-UNR lab.

The interest on this unique characteristic of remote laboratories -federating them to increase the types of practices and reduce costs- is growing. The Labshare project survey, made on all 34 Australian universities offering undergraduate engineering programs, reflects that interviewed executives were more interested in getting involved for the pedagogic merits of the remote laboratories, and that they were more inclined on initially being laboratory consumers than providers. Indeed, the

European Union Commission is going to spend 60 million euro in research actions, projects and network of excellences in Technology enhanced Learning (TEL), under the objective ICT-2011.8.1 of the call FP7-ICT-

2011-8. One of the target outcomes is precisely supporting a European-wide federation and use of remote laboratories and virtual experimentations for learning and teaching purposes. [3]

We have the possibility of letting other institutions the use of the laboratory, but the administration of the users should be done on those institutions. Unfortunately, not all universities and schools have systems to implement that, so we have to provide them a User's Management System or "MicroRLMS": a directory service to allow each institution the administration of their own users, and a way to access to the Laboratories connected to FCEIA-UNR Lab. The concept of MicroRLMS arrives from the idea that the system will facilitate administration, but not allowing the development of new laboratories. It will help with authentication and authorization combining well known technologies such as OAuth or OpenID with local databases.

\section{PREVIOUS DEVELOPMENT}

The FCEIA Remote Laboratory was created as part of a final project on the electronics engineer career by two students on 2007 [4].

It originally allowed the experimental testing of several semiconductor devices, such as diodes, bipolar junction transistors, field effect transistors and phototransistors in real time in order to obtain the output characteristics of each and to study the different behaviors in several experimental conditions.

After successive evaluations by both, teachers and students, the laboratory has been included within the syllabus to train electronic engineers in the subject Physics IV in the area of the scientific and technical foundations of common electronic devices [5].

The laboratory uses AJAX and .NET only, so it can be used with any web browser without plug-ins.

Each user can access to all of theirs previous experiments, export them to a spreadsheet (as Excel file), and download the curve as a picture (Fig. 1).

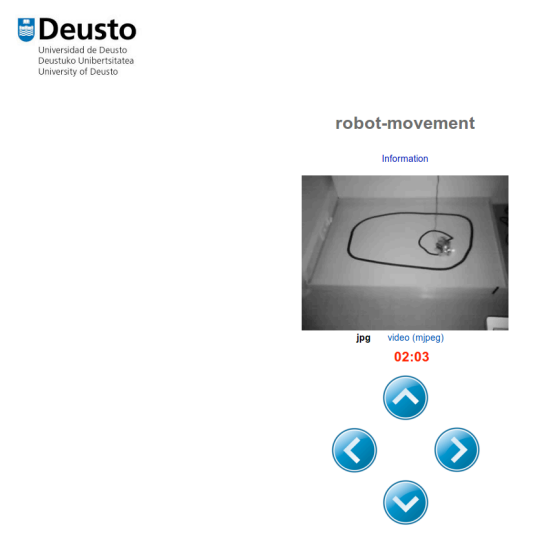

Figure 2. WebLab-Deusto robotics remote laboratory 


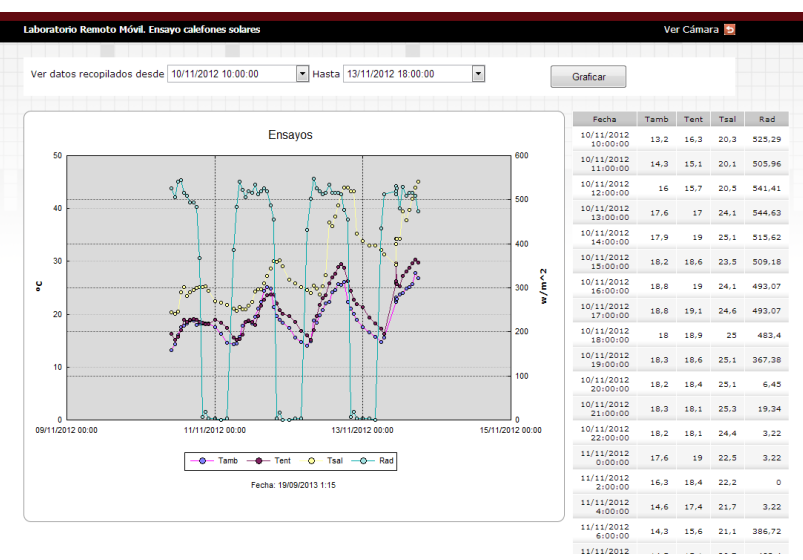

Figure 3. Solar Heater Remote and Mobile Laboratory

It is possible to modify the graphic scale on the results screen in order to improve the visualization of eventual peculiarities of the resulting curve thus allowing for better analysis. But the system does not allow the teacher to monitor the students' progress.

The improvements made year by year included a new interface, AJAX support, and the inclusion of new devices to experiment.

The last development integrated the Laboratory to educativa LMS that has been used at the university for the last years. This development allows the students' access to the Laboratory using theirs LMS user's profile to perform experiments, and send them back to the LMS to be corrected by the teacher. This improvement has been described in a previous work [6].

Later on, to the Electronics Devices Remote Laboratory, it was added a Solar Heater Remote and Mobile Laboratory [7]. The purpose of this laboratory is to measure the efficiency of solar heaters on different locations in Argentina.

Last year, our laboratories had been federated to WebLab-Deusto [8], adding several new experiments and bringing WebLab-Deusto access to ours. Also the Remote Laboratory has been translated to English language.

The growth of the FCEIA-UNR Lab and the fact that other institutions require employing thereof for teaching purposes, with an independent user administration system, make it necessary to think about developing a User's Management System.

\section{The Current Project}

Our project consists on adding to FCEIA-UNR Remote Laboratory the feature of user's administration and Social Networks integration. On this matter, at FCEIA most of the students use Facebook as primary Social Network, so it was chosen as a starting point.

This system should allow easy share of the laboratory to educational institutions (schools or universities) with no infrastructure rather than Internet access. Because of these a centralized organization from the server point of view, was selected.

The goal is to give complete autonomy to the other institutions in regard to managing their users.

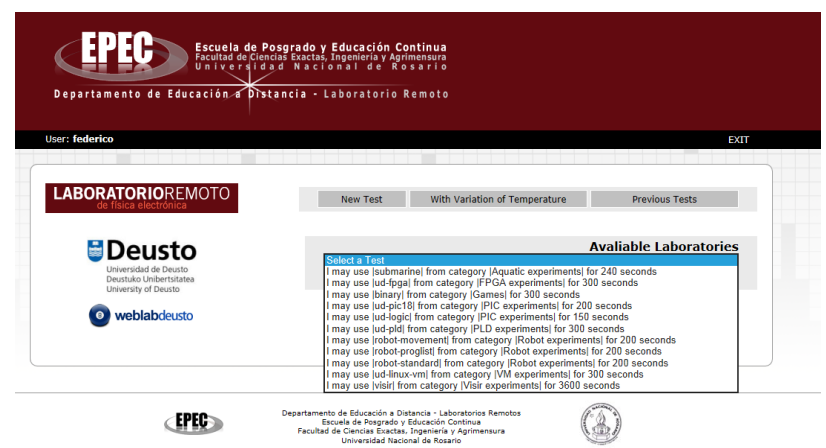

Figure 4. WebLab-Deusto from FCEIA Remote Lab

On each institution, we should have a contact person (or administrator) who has full control of its users. The FCEIA-UNR Remote Laboratory administrator will configure each institution's profile allowing access to the laboratories requested.

The institution administrator will have permission to create users (local administrators, teachers or students) as well as arrange them on different groups (classrooms). On each classroom there must be at least a teacher, who also has full control of the students on its group. On Fig 5 it is shown an organization chart.

\section{SOCIAL NETWORKS INTEGRATION}

The connection of FCEIA Remote Lab to e-ducativa LMS and WebLab-Deusto had shown that the integration of the lab and other platforms can be possible.

Social network integration is needed because most of the students at ours universities use them and so the access to the Labs is easier. Facebook is the most used one and provides several tools to ease the integration.

One of them is Facebook SDK for Javascript which was modified by a group of developers as Facebook SDK for .Net (http://facebooksdk.net/).

Using this implementation we can have a quick, easy and clean access to the Facebook's user account public information, such as username, name, profile picture, etc. with a simple JSON routine.

In Facebook we have created an application that redirects to the connection page. As any Facebook application, the user must give permission to access to theirs profile information.

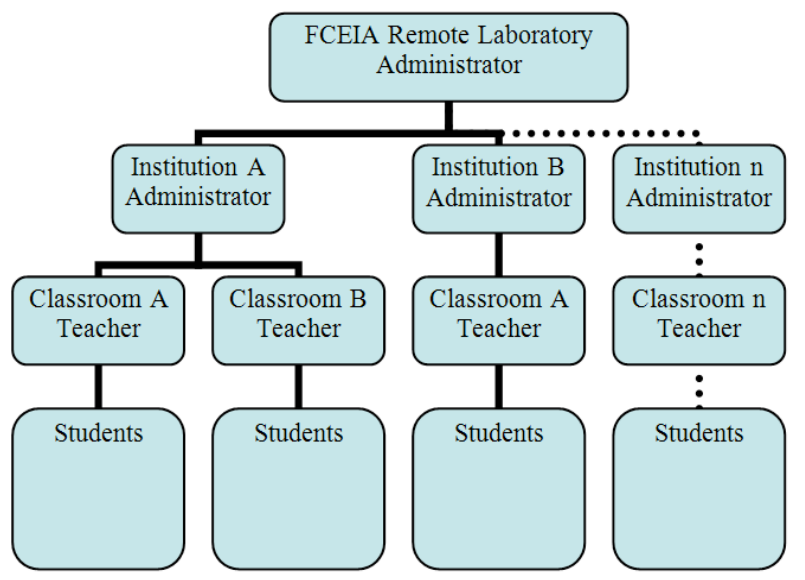

Figure 5. Basic user's administration layout. 


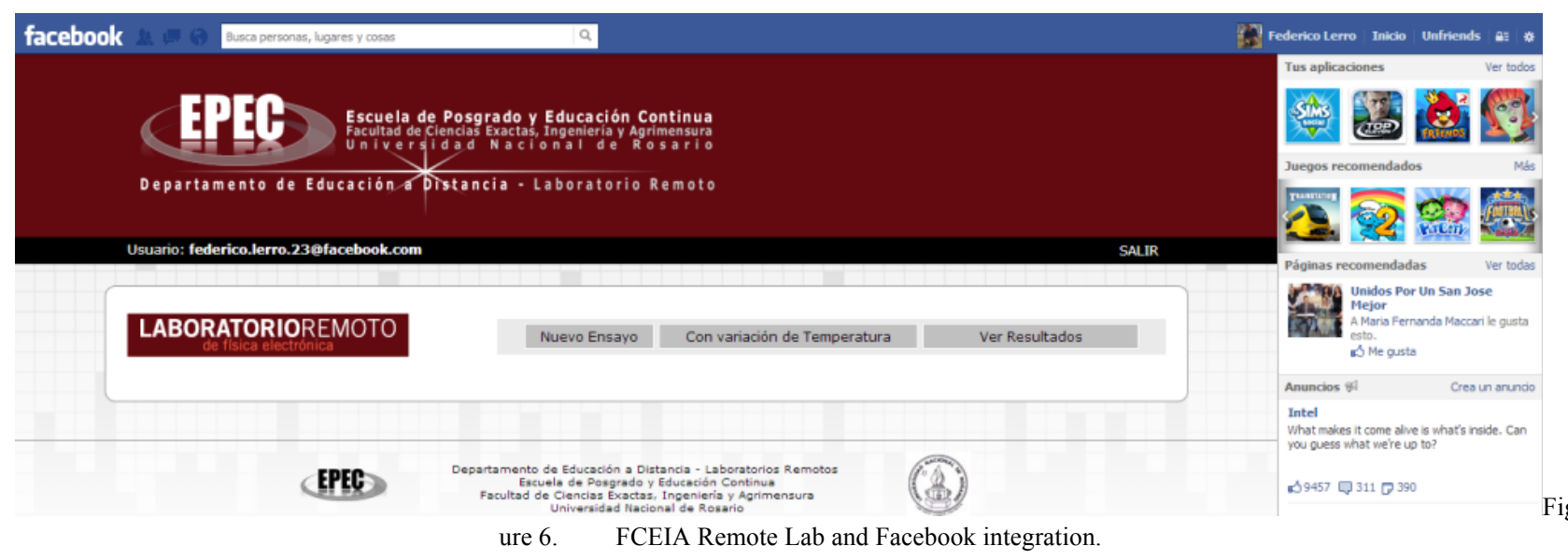

Once a new user access the Lab from Facebook, complementary information is asked, such us institution. With this information, the respective institution administrator will create the user's profile or may link the Facebook account to an existing user. If none institution is provided, the user can use the Lab as invited for a limited amount of time.

\section{AdVANTAGES AND DRAWBACKS}

We are offering a centralized administration system of our laboratory. This method offers pros and cons.

\section{A. Pros:}

The main advantage of this novel approach is that remote laboratory developers can benefit from it without having to adopt a full remote laboratory management system. They can adapt only the authentication and authorization from this microframework and automatically inherit support for multiple authentication providers (such as Facebook) in a secure way.

Deploying the system in a cloud basis, where a single infrastructure would mainly be used, provides a centralizing structure. This centralization eases the sharing of remote laboratories, since using a global authorization it becomes easy to enable certain groups of other universities to access the remote laboratories. If University A adopts this solution for Remote Laboratory 1, and University B also adopts it for Remote Laboratory 2, University B can share their remote laboratory with University A even if the rest of the remote laboratory stack (scheduling, technologies, etc.) are different, by simply indicating that they can access those labs.

Finally, using this microframework approach, remote laboratories can adopt this solution with a low learning curve compared to the traditional RLMSs (e.g., WebLabDeusto, iLab Shared Architecture or Sahara), since the rest of the remote laboratories stack can be implemented in other technologies. However, this approach is not incompatible with traditional RLMSs: by adding the support to them for this microframework in their authentication or authorization mechanisms, all the remote laboratories built on top of them could also benefit from the rest of the advantages.

\section{B. Cons:}

While deploying the solution in a cloud basis (with a single instance managing all the laboratories) improves the visibility of the different labs by enabling remote labs providers to share them with other institutions easily, this type of deployment also adds other drawbacks.

First, a centralized authentication system may not be able to access authentication information accessible only from the institution network. For instance, directory services such as LDAP are popular in institutions and are typically only accessible through their local network for security reasons. An external, centralized system will not be able to use it, so if the institution does not support other systems (such as Shibboleth or OpenID), the system might require users to be registered in the cloud service.

The second major drawback is that it introduces a single point of failure. Even if the system is deployed in an enterprise level cloud provider (such as Amazon), it might fail at some point, and in that point all the remote laboratories attached might not be usable from this system. From a security perspective, this centralized approach aggregates more information in a single system, so a successful attacker might acquire access to all the remote laboratories.CONCLUSIONS

During the last ten years, remote laboratories have been created all over the world, as a complement to regular education or as main components on e-learning courses. The interoperability of these remote Labs between each other has become on the next step [1].

The possibility of integration and interoperability enables that the users of any laboratory A can access to others laboratories from others institutions with more experiments.

We agree with Barab \& Plucker [9], when they say that in education we are moving from cognitive theories that emphasize individual thought and isolated minds, to the theories that emphasize the situational nature of cognition and meaning. In this context, and considering the fundamental role that experimentation has in technological training, we emphasize the importance of encouraging the development of learning processes based on real experimentation. And much better, of combining such practical training with participation, interaction and collaboration processes. 


\section{FURTHER DEVELOPMENTS}

Similar integration systems can be used to authenticate and authorize users from others Social Networks as Google, LMS as Moodle or others universities with local systems.

\section{REFERENCES}

[1] Orduña, P.; Lerro, F., Bailey, P., Marchisio, S., DeLong, K., Perreta, E., Dziabenko, O.; Angulo, I.; López-de-Ipiña, D., GarciaZubia, J. (2013) Exploring complex remote laboratory ecosystems through interoperable federation chains. 4rd IEEE Global Engineering Education Conference (EDUCON). Berlin, Germany. March 2013.

http://www.weblab.deusto.es/web/images/publications/educon201 3 interop.pdf

[2] Lerro, F., Marchisio, S., Perretta E., Plano, M., Protano, M. Using the Remote Lab of Electronics Physics ("Laboratorio Remoto de Física Electrónica") to Support Teaching and Learning (2012) pp.211 -230, in García Zubía, J y Alves, G. (comp.) "Using Remote Labs in Education". Universidad de Deusto http://www.deusto-publicaciones.es/index.php/main/libro/913

[3] Orduña, P.; Larrakoetxea, X.; Buján, D.; Angulo, I.; Dziabenko, O.; Rodriguez-Gil, L.; Lópezde-Ipiña, D.; García-Zubia, J. (2013). WebLab-Deployer: exporting remote laboratorios as SaaS through federation protocols. In Remote Engineering Virtual Instrumentation 2013, REV 2013, February 2013

[4] Lerro, F. \& Protano, M. (2007). Web-based Remote Semiconductors Devices Testing Laboratory. International Journal of Online Engineering, 3(3), 1-4.

[5] Lerro, F.; Marchisio, S.; Plano, M.; Protano, M.; Von Pamel, O. (2008) A remote lab like a didactic resource in the teaching of the physics of electronic devices, Proceedings 11th International Conference on Interactive Computer aided Learning; September 24 26, 2008. Villach.

[6] Lerro, F., Marchisio, S., Martini, S., Massacesi, H., Perretta, E., Gimenez, A., Aimetti, N, Oshiro, J. (2013). Realización a Distancia de Experimentos Reales desde un Sistema de Gestión de Aprendizajes. Revista VAEP-RITA. 2013. V1.N2.
http://rita.det.uvigo.es/VAEPRITA/index.php?content=Num Pub \&idiom=Es\&visualiza $=1 \&$ volumen $=1 \&$ numero $=2 \&$ orden $=\overline{\mathrm{desc}}$.

[7] Saez de Arregui, G., Plano, M., Lerro, F., Petrocelli, L., Marchisio, S., Concari, S., Scotta, V. (2013). A Mobile Remote Lab System to Monitor in Situ Thermal Solar Installations. International Journal of Interactive Mobile Technologies, 7, 31-34. http://www.online-journals.org/index.php/i-jim

[8] Orduña, P. (2013). Transitive and Scalable Federation Model for Remote Laboratories. PhD thesis, Universidad de Deusto, 2013. http://www.weblab.deusto.es/pub/dissertation_pablo.pdf

[9] Barab, S., A., \& Plucker, J. A. (2002). Smart people or smart contexts? Cognition, ability, and talent development in an age of situated approaches to knowing and learning. Educational Psychologist, 37(3), 165-182. http://dx.doi.org/10.1207/S15326 $\underline{985 \mathrm{EP} 3703 \quad 3}$

\section{AUTHORS}

F. Lerro is with the Facultad de Ciencias Exactas, Ingeniería y Agrimensura - Universidad Nacional de Rosario (UNR), Avda. Pellegrini 250, Rosario, Argentina (e-mail: flerro2@yahoo.com.ar).

P. Orduña., is with the DeustoTech - Deusto Institute of Technology, University of Deusto, Avda Universidades 24, 48007 Bilbao, Spain (e-mail: pablo.orduna@deusto.es).

S. Marchisio is with the Facultad de Ciencias Exactas, Ingeniería y Agrimensura - Universidad Nacional de Rosario (UNR), Avda. Pellegrini 250, Rosario, Argentina (e-mail: timbucorreo@gmail.com)

J. García-Zubía is with the Faculty of Engineering, University of Deusto, Avda Universidades 24, 48007 Bilbao, Spain (e-mail: zubia@deusto.es).

This article is an extended and modified version of a paper presented at the ICBL2013 International Conference on Interactive Computer aided Blended Learning, held 6 - 8 November 2013, in Florianópolis, Brasil. Submitted 29 April 2014. Published as resubmitted by the authors 07 August 2014. 